\title{
Preservation criteria applied to the case study of a 19th century fortress
}

\author{
C. Mileto, F. Vegas, V. Cristini \& J. R. Ruiz-Checa \\ Universitat Politècnica de València, Spain
}

\begin{abstract}
The strategic importance of Mahón Harbor (Menorca Island, Spain) is developed over several centuries until the point when the enclave is definitively fortified, due to the increasing of Anglo-French shipping routes antagonism in the 1840s. Currently the Fortress of La Mola (1852) is one of the better preserved Spanish examples of military architecture, due to the harbor's dimensions, its depth and protection from the dominant winds in the western Mediterranean. In the frame of maintenance projects, carried out in the complex, the authors have made a preservation project that is focused on two specific elements: Recess Five and the Princess Tower. Recess Five consists of a defensive element in the shape of a pincer or tongs with a redoubt in the recess angle; it forms part of the traditional polygonal defensive system. The containing wall suffered $40 \mathrm{~cm}$ of subsidence and the $13 \mathrm{~m}$ high stretch of wall was in an advanced state of disrepair, making careful preservation work necessary (2013). On the other hand, the Princess Tower is a building documented prior to construction of the fort (1798-1802). It is later incorporated as a tactical element in the ambitious project of the Fortress of Isabel II. Preservation work (2013) has concentrated on 'freezing' the moment of the explosion, suffered in the tower's interior in 1958. The ruin thereby remains a focal point of the scene, showing the effect of the explosion, and preserving this 'piranesian' image, valuing fragments and layers as constructive prints of a long, historical process.
\end{abstract}

Keywords: preservation project, consolidation, military architecture, stratigraphic study.

\section{Introduction: La Mola Fortress}

Minorca is a strategic location in the Mediterranean and for this reason its port has undergone different fortification efforts over time. The first was the construction 
of St. Philip's Castle (Castillo de San Felipe) in the mid-sixteenth century, to the right of the entrance to the port of Mahón. This fortress was the scene of many clashes, notable among them those that resulted in the subsequent occupation of the island by the British (1708-1756), the French (1756-1763), the British (17631782), the Spanish (1782-1798), the English (1798-1802), returning to the Spanish, from that date, under the Treaty of Amiens. This fortress was subject to several successive destructions and reconstructions, until it was finally demolished by Charles IV in 1805 [1].

Half a century later, when military defences were being renewed in the light of the transformation of armaments and of the very same concept of war strategy, and considering the defensive criteria of the reign of Isabel II, focused on the need of defending the coastal border, La Mola fortress was devised to be erected to the left of the entrance to the port of Mahón. This fortress would be positioned in a line of maritime defence, with batteries capable of attacking enemy fleets and a fortification with the ability to protect troops and repel land attacks. (Figure 1) [2].

The construction process of such fortification would be tortuous, subject to economic injections, to the changes in the construction process, and technical disagreements. Started in 1848, it would last more than 25 years.
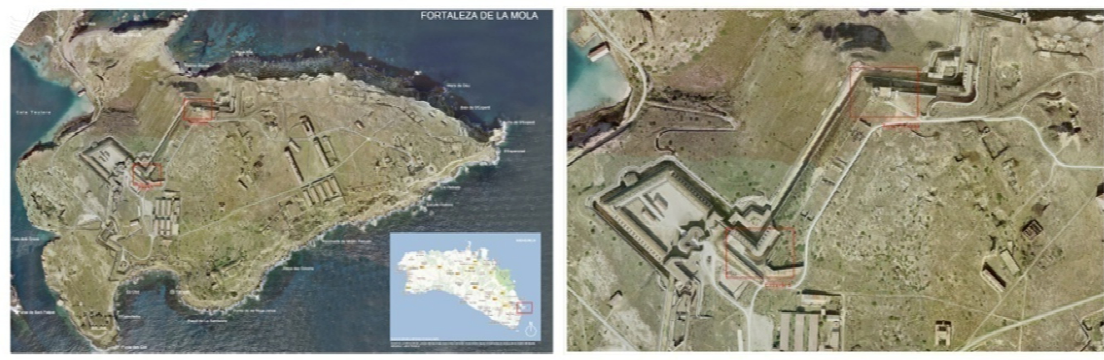

Figure 1: Island of Minorca and location of La Mola fortress (authors).

\section{The sites of intervention}

A series of feasibility studies and works of conservative intervention were conducted respectively during 2011 and 2013 in two parts of La Mola fortress, the Recess 5 and the Princess Tower.

Historically, what is known as Recess 5 consisted in a pincers-shaped defensive element with a redoubt at the incoming angle (Figure 2). The straight retaining wall of the pincers connecting the outgoing angle of the Princess Tower and the Recess 5 stretched for a length of $390 \mathrm{~m}$, closing the landward defence [3]. This series of works - consisting of the straight section, the Recess 5 and its redoubt — began in 1850 and would carry on until 1860, and integrate a perfect example of a polygonal landward defence, in keeping with the fortification theories of the time $[4,5]$. 

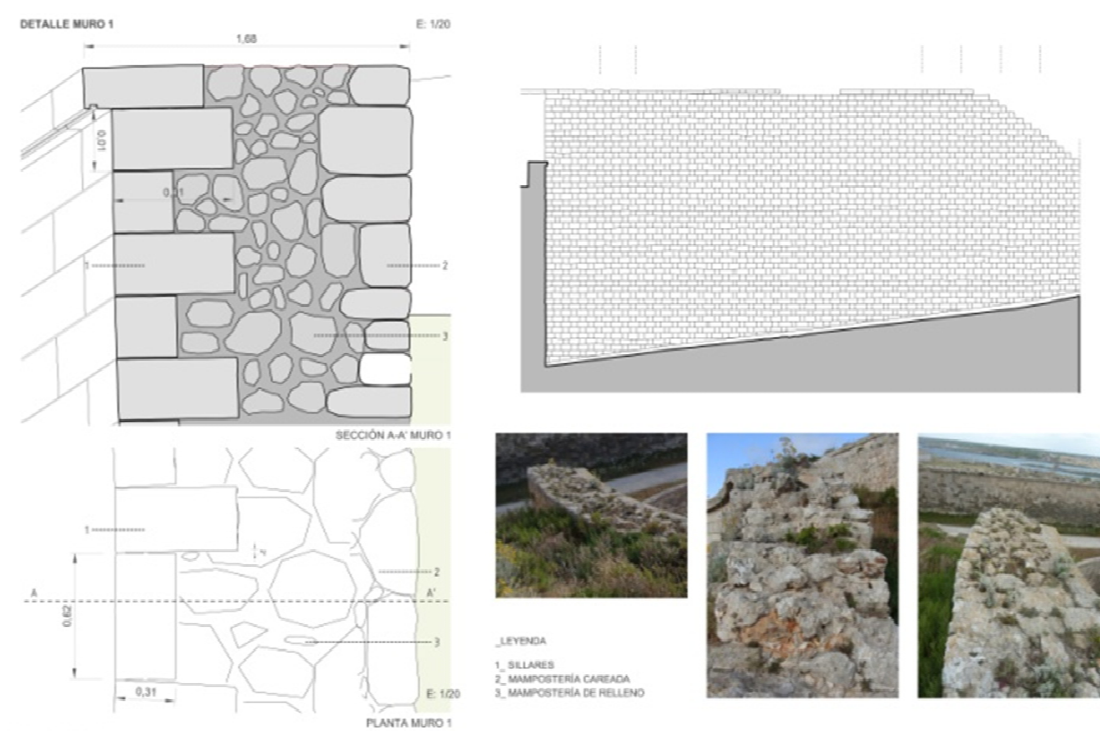

Figure 2: Constructive details, Recess 5 (authors).

The Princess Tower, also called Erskine Tower or Torre Los Freus, has witnessed the faith in the dispersed defence based on the strategic location of standalone towers, which spread in Europe after the tower of Mortella (Myrtle) Point wreaked havoc on the British fleet in 1794. Specifically, the Princess Tower was built by the British in 1799 as a standalone Martello tower and later became part of the new layout of La Mola fortress in salient 3 of the whole structure, as if it had always been a part of it. This inaccessibility by land emphasized the efficacy of the Tower, which was characterized by the small number of garrison troops required to operate it. Its base was reinforced to resist ground attacks, and the door was risen above the ground level, covered by a vertical fire provided by a simple machicolation above it. The tower base typically housed warehouses and water tanks. The first level, vaulted and artillery-proof, featured loopholes and vertical vents (Figure 3).

\section{Preservation conditions}

The Recess 5, being a section of the defensive wall of the fortress which acts as a retaining wall, was in a terrible condition, due to earth pressures. The section under study had a length of $30 \mathrm{~m}$ and a height of $15.07 \mathrm{~m}$ at the highest point. Prior to the intervention, the Recess 5 showed significant degradation, erosion and pulverization of many of the blocks of stone that formed the retaining wall. In addition to this, the entire wall was visibly collapsed; even some of the capstones were missing. 

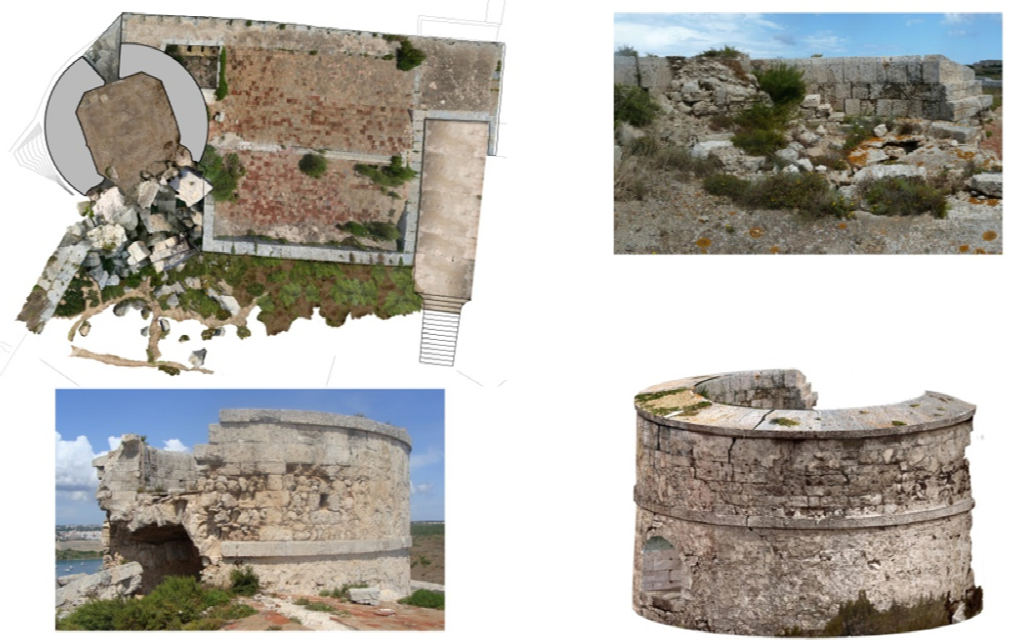

Figure 3: The Princess Tower, details (authors).

On the other hand, prior to the intervention, the Princess Tower presented a delicate state of preservation, being partially demolished on the inside due to an explosion caused by a lightning strike in 1958, when it was used as a gunpowder magazine. Neither the access nor the tower's stairway were preserved, but the embrasure facing north (towards the sea) remained standing. The tower had a circular plan and a slightly truncated cone-shaped morphology, with an upper radius of $5.06 \mathrm{~m}$ and a maximum height of $8.26 \mathrm{~m}$, with a total floor area of $80.41 \mathrm{~m}^{2}$. Its morphological characteristics were completed by the presence of a barbette on the upper rampart, usually for two or three heavy guns (32- and 36pounder bronze naval cannons with rotating carriage). Its base was reinforced to resist ground attacks, and the door was risen above the ground level, covered by a vertical fire provided by a simple machicolation above it. The tower base typically housed warehouses and water tanks. The first level, vaulted and artillery-proof, featured loopholes and vertical vents.

\section{Construction stages}

As previously indicated, the construction process of the fortification has been complex, both from an economic standpoint and a technical-constructive perspective. For this reason, the feasibility study has put particular emphasis on the historical documentation and possible stratigraphic study of the Recess 5 and the Princess Tower.

Constructively, the Recess 5 is homogeneous, built throughout the same construction stage, which coincides with a single relative chronology, while the Princess Tower has different stages of execution. 
In the masonry of the tower, we have identified three periods corresponding to a relative chronology, i.e. without a direct relationship to accurate historical dates. Each of the three periods in turn comprises various stages of construction corresponding to different work cycles.
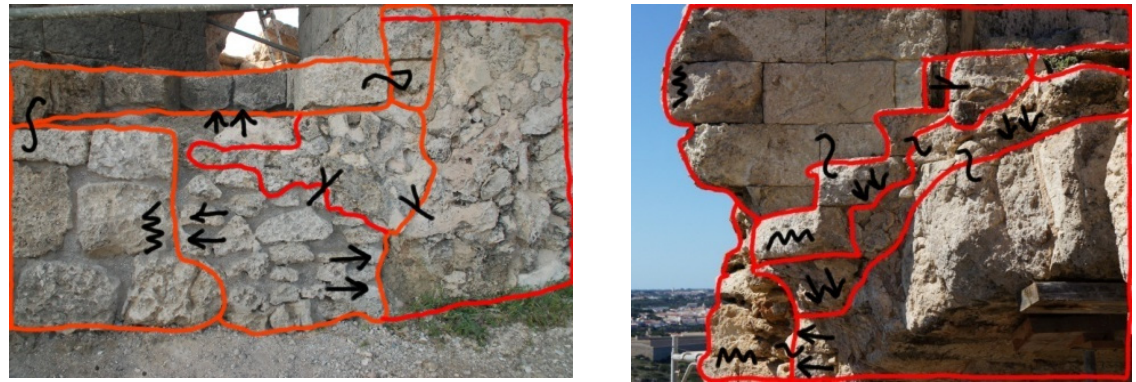

Figure 4: The Princess Tower, stratigraphic details (authors).

The first period corresponds to the original works on the tower, carried out before the construction of the fortress of Isabel II (1798-1802). This stage is characterized by the presence of two-sided walls, with regular blocks of sandstone, prepared, having a masonry filling core and lime-based mortars with fine aggregates.

The building work with chain reinforcements and chains of masonry piers, whose remains have survived only in part to the explosion, possibly dates back to this stage [6].

The second period is related to the works of 'renovation' and 'repair' of the tower, carried out during the construction of the fortress of Isabel II (1850-1875). This stage is characterized by the presence of the barbette on the upper rampart, built with the 'abeurada' technique (explained below), whose traces are visible in the wreckage of the explosion. In addition, a number of repair and finishing mortars are recognizable, suggesting possible interventions on the surface of the tower.

The third period corresponds to the construction and addition of the guardhouse, possibly in the late nineteenth century (Figure 4). In this case, the structure is built with autonomous and different construction techniques from those employed for the tower: regular blocks of reduced size and lime mortar with dense aggregate of metamorphic origin [7].

\section{Intervention criteria}

By arrangement with the Spanish Cultural Heritage Institute and the military structure owner of the fortress, we have established the following criteria for intervention. With regard to the Princess Tower, despite the relative ease of rebuilding and anastylosis of the stones detached in the explosion, we have seen fit to preserve the ruin with all its strength and Piranesian character. This ruin preservation should go hand in hand with a structural consolidation and 
reinforcement of the elements that would avoid further collapses, not to mention the physical preservation of its masonry and plasterwork to curb its progressive deterioration.

As for the Recess 5, the needs expressed in general terms have focused on the conservation of the wall and to ensure the safety of visitors. For this reason, it has been necessary to undertake a structural consolidation of the affected wall, with the protection and repair of the crown, the consolidation of deteriorating stone, the attenuation of the phenomena of degradation, the elimination of the causes of moisture, and the resolution or contrast of the earth pressure forces (Figure 5).

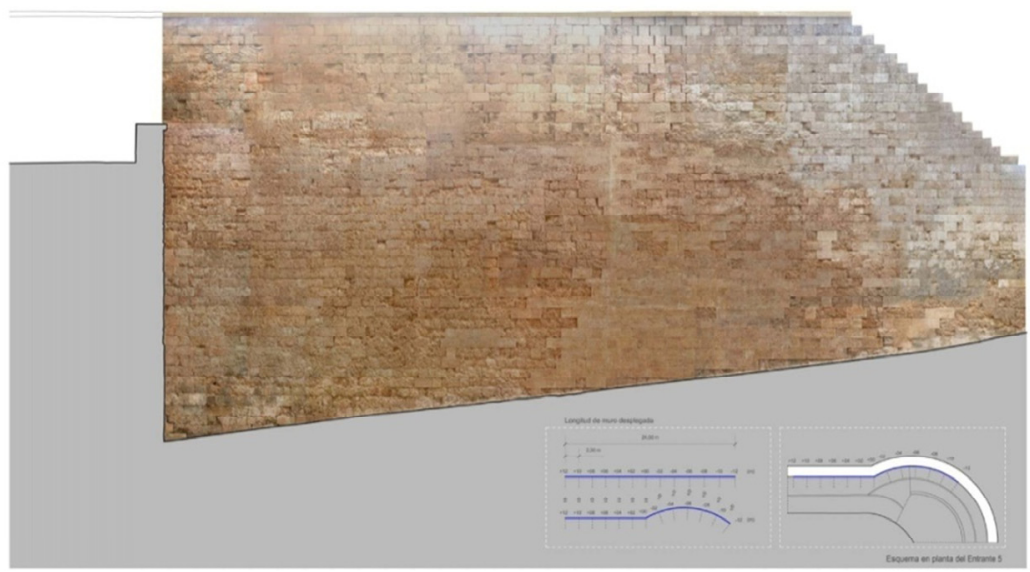

Figure 5: Recess 5 after the intervention (authors).

As you can see, the criteria for action in both places have been different since the needs to address were different. In the case of the Princess Tower, the desire to preserve a romantic ruin in its fresh, spontaneous and original state, had to take into account the considerable difficulty of trying to combine the necessary safety of visitors with the spontaneity and complexity of preventing its deterioration despite its exposure to the elements. In the case of the Recess 5, it was to repair a wall with reduced structural capacity and a major collapse so that it could continue to perform its containment purpose, with the possible inclusion of missing stones, while ensuring that any intervention would not alter the patina and the venerable character of its sesquicentennial masonry.

\section{Intervention}

The criteria identified in the previous section have led different intervention plans, articulated and detailed for the Recess 5 and the Princess Tower, as summarized below. 
One of the first actions carried out in the intervention, has been the determination of the characteristics and behavior of the land contained behind the wall of the Recess 5 . The significant collapse suffered by the wall surface under intervention ( $46 \mathrm{~cm}$ in $12 \mathrm{~m}$ of height), was the result of earth pressures in the area behind it. Thus, to solve the problem, a partial emptying of the backfill of the wall has been carried out, up to $6 \mathrm{~m}$ deep, and the intrados has been propped up over the entire surface to sustain the thrusts produced during the work.

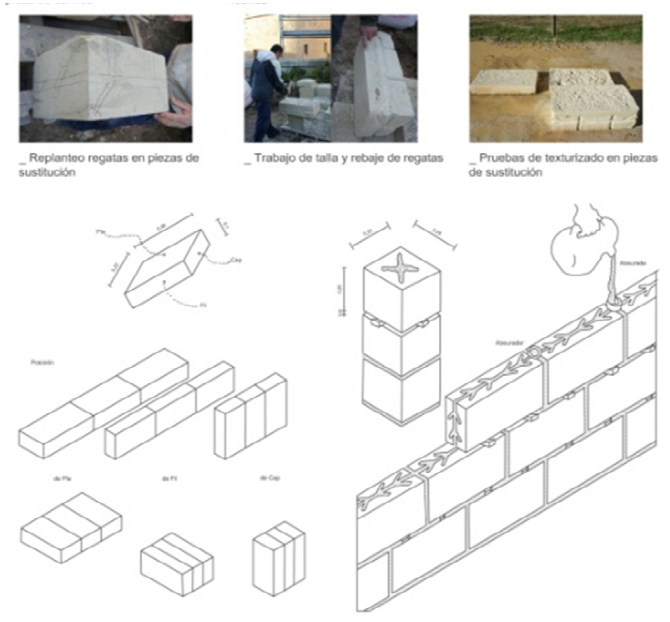

Figure 6: Technical process of 'abeurada' in Recess 5 (authors).

Planning the delicate intervention on a stone masonry made up of almost 3000 pieces required relying on a coding system to facilitate the identification of the pathology and its consequent repair. This coding system has also been extremely important for the financial management of the project, as it has allowed to predict the cost of each work to carry out (the final amount for the project has coincided with the initial budget). For that, a key point of the intervention has been the study of the ashlars of the wall, characterized by a thickness of $1.60 \mathrm{~cm}$ and consisting of three layers. The first, primed with masonry and hydraulic lime mortar, corresponding to the exterior surface of the wall; a second external layer primed with a diatonic mixture (stretcher and header bond) of blocks of sandstone $(30 \times$ $60 \mathrm{~cm}$ ) and hydraulic lime mortar, corresponding to the lower surface of the wall; and finally a wall filling with gravel of different particle size and a matrix of hydraulic lime concrete. At the same time, we performed a comprehensive analysis of the techniques employed during construction.

The precision at the joints, whose thickness varies between 2 and $3 \mathrm{~mm}$, has demonstrated a high quality in the workmanship. The slightly truncated coneshaped cut of the pieces was also notable: both setting the pieces in place and pouring the grout into the joints and sutures has been easier thanks to this particular geometry. 
The presence of channels is also clear evidence of the use of the traditional 'abeurada' technique, frequently employed throughout the fortress. Such technique is based on creating a network of grooves on the hidden side of the pieces, thus facilitating the entry of lime whitewash (Figure 6). Small exterior sealing joints (with 'bastard' lime and plaster mortar) are created to prevent the leakage of the grout through the exterior joints. With this technique we proceeded to the replacement of nearly 500 pieces of the whole structure, whose finish has been carefully treated, using water-sandblasting calibrated to different levels of erosion depending on the final destination of each piece [8].

Similarly, after the materials analysis in the Recess 5, we proceeded to characterize the Princess Tower and the roof of the guard-house. A relevant aspect in the documentary and archaeological analysis, conducted throughout the preservation project, has been the discovery of sgraffito incisions in some fragments of cladding. Another element of interest found during the archeological survey of the tower's surroundings were the tracks corresponding to artillery pieces, and what might have been the rails of a crane for vertical transportation, like the Krupp 80 [9]. One of the most important challenges of the intervention has been to fix the variety of fissures on the double vault and the north side of the tower. The intervention on the fissures required the partial underpinning of the vault, with the goal of setting up 40 stitching points, as to ensure its stability. Finally, the perforations were filled with epoxy resin. The volume of the fissures and the perforations was filled with slightly expansive mortar to facilitate the load testing of the vault after the striking.

The uneven and cracked state of the tower's roof required levelling it and ensuring water evacuation through a bed of lightweight concrete made with arlite and subsequently a base slab of natural hydraulic lime mortar. On the other hand, it is important to identify the restoration work that has focused on the exterior cladding and the roof of the guard-house. Intervention on these elements included selective cleaning, micro-sealing, consolidation of loose mortars, filling gaps, general harmonization and consolidation (Figure 7).
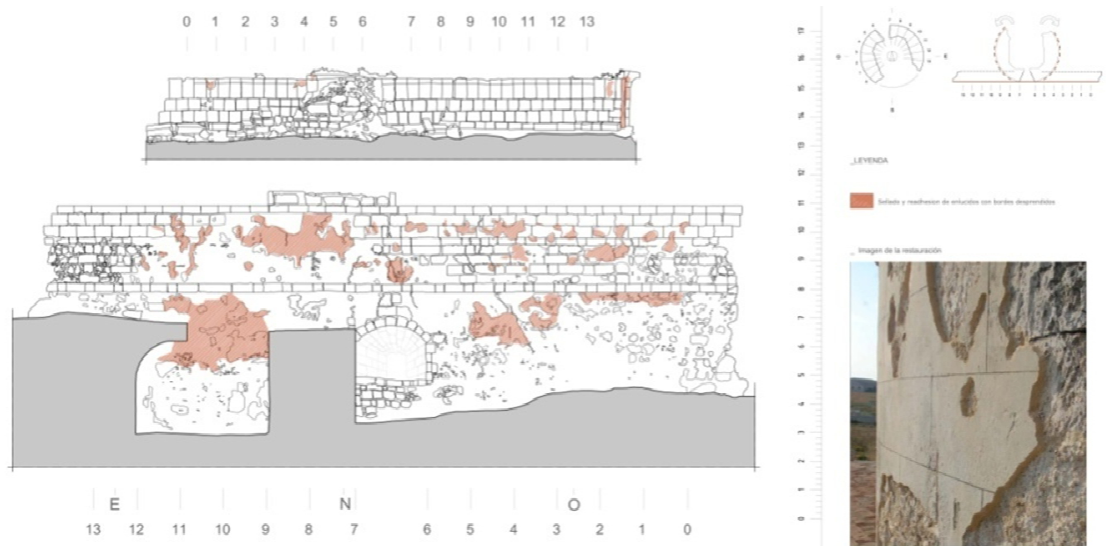

Figure 7: Details of mortars consolidation, The Princess tower (authors). 


\section{Results}

In a highly strategic context such as La Mola fortress in the port of Mahón (Minorca, Spain), the feasibility study and preservation project carried out in the Recess 5 and the Princess Tower in particular, have enhanced the construction quality of the structure [10], all of which resulting from the combination of a great tradition of local masonry and the use of numerical computation. The preservation works have been mainly aimed at the stabilization of the two elements. Prior to these interventions we performed a thorough diagnosis of structural pathologies and alterations. By following environmentally friendly intervention criteria, the results of the work have led to a discrete reading of the areas of operation, reinforcing the constructive and stratigraphic lesson of these two structures. The selective process of consolidation, reinstatement or replacement of stone elements, carried out in the two structures has guaranteed their iconic status in the setting of the fortress.

\section{References}

[1] AA.VV. Memoria 1998-2013, Consorcio del Museo Militar de Menorca y patrimonio histórico Militar del Puerto de Mahón y cala San Esteban Ed.: Menorca, 2013

[2] Català J., La Mola, Fortalesa Isabel II, Triangle Postals Ed.: Menorca, 2008

[3] De Nicolás Mascaró, J.C., Talaies $i$ torres de defensa costaneres, Institut d'Estudis Baleàrics, Institut Menorquí d'Estudis: Mahón, 1994

[4] Fornals Villalonga F., Torres defensivas de Menorca, Consorcio Museo Militar Ed.: Menorca, 2006

[5] Fornals Villalonga F., Patrimonio del Consorcio del museo Militar de Menorca, Ministerio de Defesa Ed.: Madrid, 2002

[6] Fornals Villalonga F., Fortaleza de Isabel II en la Mola del Puerto de Mahón, siglos XIX y XX, Gràfiques Menorca Ed.: Menorca, 2010

[7] Fornals Villalonga F., El cuerpo de ingenieros del ejército en Menorca, siglos XIX y XX, Consorcio del Museo Militar de Menorca y Patrimonio histórico Militar del Puerto de Mahón y cala San Esteban Ed.: Menorca, 2011

[8] García Inyesta N., Olivier Sunyer G., Construir en marés, Coal Baleares Ed.: Baleares, 1977

[9] Terrón-Ponce, J.L. La fortaleza de Isabel II en el puerto de Mahón, Estudio arquitectónico y análisis táctico, Museo Militar Ed.: Mahón, 2004

[10] Viller Ribas M., Arquitectura y paisatge de Menorca, Triangle Postals Ed.: Menorca, 2006 